\title{
Experimental Investigation of Engineering Materials under Repetitive Impact with Slurry Conditions
}

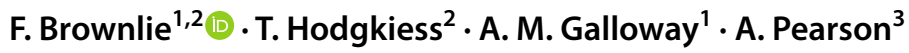

Received: 2 October 2020 / Accepted: 20 November 2020 / Published online: 8 December 2020

(c) The Author(s) 2020

\begin{abstract}
In some industrial situations, components are subject to repetitive impact in the presence of a slurry. A novel repetitive impact-with-slurry test rig was developed to evaluate the behaviour of a wide range of engineering materials in such conditions. The test materials could be categorised into five main groups - heat treated steels, stainless steels, chromium cast irons, hardfacing coatings and superalloys. Three-dimensional surface topography was used to quantify the depths and volumes of the produced wear scars. Post-test metallurgical examination was also conducted to further evaluate the wear processes. The wear mechanisms could be split into two main groups of materials; ductile materials were observed to plastically deform and hard/brittle materials demonstrated cracking/spalling mechanisms. Hardened martensitic-type materials exhibited the greatest resistance to repetitive impact wear.
\end{abstract}

Keywords Repetitive impact $\cdot$ Slurry $\cdot$ Engineering materials

\section{Introduction}

Repetitive impact wear is described as recurring solid body impacts, where the contacting surfaces are wearing [1]. There are two types of repeated impacts. When there is a tangential or rotational element which results in sliding or rolling, this is referred to as compound impact. When there is no rotational or tangential element, this defined as normal impact.

Engineering components used for fluid transport such as valves (globe, check and dart) that are employed in the oil and gas as well as power generation industries, experience repetitive impact wear. In the mineral processing industry, components such as crushers, breakers and sizing screens also experience material loss due to repetitive impact damage $[2,3]$.

A variety of experimental set-ups have been developed to assess repetitive impact wear of materials for different

F. Brownlie

f.brownlie@strath.ac.uk

1 Department of Mechanical and Aerospace Engineering, University of Strathclyde, Glasgow, UK

2 Weir Advanced Research Centre, Glasgow, UK

3 Ascott Metallurgical Ltd, Glasgow, UK engineering applications. Five main types of such test rigs have been identified: reciprocating pin on disk, pivot hammer, high velocity impact gun, ball on plate and repetitive impact with dry abrasion. A brief summary of each type of repetitive impact wear test rig, the relevant engineering applications and the main material degradation mechanisms are discussed below.

\subsection{Reciprocating Pin on Disk}

The pin on disk wear testing method is typically used to assess the sliding wear resistance and coefficient of friction of materials [4], however, this testing apparatus has been adapted by researchers with the capability of testing both compound impact wear and transverse sliding wear [5]. This is aimed at engineering components that experience sliding wear with repeated impulsive loading, such as; cams and followers, mating gear teeth and mechanical linkages [6].

Parameters such as impacting velocity, sliding speed, number of cycles, load, frequency, system damping and stiffness have all been studied as testing variables [5]. However, the adapted testing apparatus is limited to small loads and sliding velocities, less than $1 \mathrm{kN}$ and $8 \mathrm{~m} \mathrm{~s}^{-1}$ respectively. These low loads and velocities mean that a large amount of cycles are required before any measurable damage occurs. These tests are conducted under dry conditions. 
From reciprocating impact wear test machines, three subsurface zones are found to be present after each test; undeformed base material, plastically deformed base material and a white compound layer with a compositional mixture (combination of material from both impacting bodies) [5, $7,8]$. These zones have been found to be present in a wide range of metallic materials such as; low alloy steels, stainless steels, titanium, aluminium, aluminium-copper and copper alloys [6, 8-12]. The subsurface zones have been found to be present as a result of the various wear mechanisms such as plastic deformation, ploughing, delamination, smearing and material transfer [6, 8-13]. Metal-matrix composite materials (HVOF coatings, etc.) exhibit fatigue cracks as well as plastic smearing as the main degradation mechanisms [14, $15]$.

\subsection{Pivot Hammer}

Pivot hammer tests have represented another method used extensively to assess repetitive impact wear for a variety of engineering applications such as poppet valves and seats in automotive engines, reciprocating valve components, machine elements (cams and gears) and electrical connectors used in the computer and telecommunication industries [16-19]. The conditions for pivot hammer tests range from 2-200 N applied load, up to $10^{9}$ cycles and operate at a frequency up to $50 \mathrm{~Hz}$ [16-20].

The main findings have been that metallic alloys exhibit an initial wear period, followed by a zero wear stage (plastic deformation only) and finally by a measurable wear phase $[18,20]$. The main wear mechanisms for metallic alloys have been observed to be plastic deformation, pitting and surface traction (wet conditions - distilled water) and surface heating (dry conditions) [16-18, 20]. For ceramic materials, the main wear mechanisms are micro-fracture and platelet formation [19].

\subsection{High Velocity Impact Gun}

High velocity impact guns are used for impacting individual particles at extremely high velocities. This type of testing apparatus has been developed to study the erosion processes occurring in applications such as mining, coal gasification, helicopter parts and short take-off and landing aircraft [21, 22]. Particles vary in size from $100 \mu \mathrm{m}$ to $2 \mathrm{~cm}$ and velocities range from $44 \mathrm{~m} \mathrm{~s}^{-1}$ to $1210 \mathrm{~m} \mathrm{~s}^{-1}$ [21-25]. A variety of materials are used for the impacting particles such as zirconia, hardened steel, tungsten carbide and silicon nitride [21-25]. The high velocity impact gun experiments are conducted in air.

Different types of wear mechanisms have been observed to be associated with the impacting angle of the particle. At low, oblique angles lip formation and fragmentation have been observed [21, 22]. Whereas, at high impact angles thermal softening, flake formation, shear deformation, strain localisation and adiabatic shear bands are more likely to occur $[21,22,24,25]$.

\subsection{Ball on Plate}

Ball on plate testing devices use spherical balls (often tungsten carbide) to create repetitive impact damage. The loads used in these studies are less than $1 \mathrm{kN}$ and are often in the magnitude of $10^{3}-10^{6}$ cycles and tests are conducted under dry conditions. They are commonly used to assess the adherence of thin surface coatings such as Diamondlike Carbon (DLC) and Physical Vapour Deposition (PVD) coatings [26-29].

A white compound layer with a plastically deformed zone has been observed in some studies of metallic alloys as well as adiabatic shear bands. These often lead to nucleation of micro-voids as well as surface cracking and flaking [30-33]. For hard ceramic coatings, the main material degradation mechanisms have been observed to involve surface and subsurface micro-cracking which lead to spalling and delamination of the coatings [34-36].

\subsection{Repetitive Impact with Dry Abrasion}

Due to the high wear rates found in hydraulic rock crushing equipment, repetitive impact test rigs have been designed to incorporate the dry abrasive "crushing" effects of rocks. The test conditions include high loads up to $86 \mathrm{kN}$ and test durations up to 1000 cycles [37, 38].

A good correlation has been observed between increased hardness and increased resistance to impact-abrasion [37-42]. The main wear mechanisms have been found to be indentation, plastic deformation and micro-scratching [37, 38, 40-44]. Micro-cracking has been observed in materials with carbides [39, 45, 46].

In summary, the available literature, regarding studies using repetitive impact test machines, has demonstrated that the main damage processes occurring during repetitive metal-metal impact are interactions between plastic deformation and cracking. Although a large number of variations of testing equipment and conditions have been investigated, many of these (e.g., stress levels, number of cycles, dry conditions, etc.) are not especially relevant to many engineering components and applications which experience repetitive impact wear with slurry. There appears to be no standard test rig which incorporates repetitive impact with high compressive loads and abrasive sand particles in an aqueous solution. Therefore, it was clear to the authors that a purpose built rig was required to investigate this type of wear.

The study described herein, describes a novel custom test rig which has been used to assess a wide range of 
engineering materials and coatings under repetitive impact wear with slurry conditions. Detailed post-test analysis using surface profilometry and metallurgical examination has been used to rank and characterise the material degradation processes.

\section{Methodology and Materials}

\subsection{Methods}

The repetitive impact-with-slurry tests were conducted using a Zwick Roell 2061 hydraulic testing machine. The tests were conducted with a compressive load of $32 \mathrm{kN}$ applied at a frequency of $5 \mathrm{~Hz}$. Each test ran for a total of 50,000 cycles. A custom-made impactor which was cylindrical with a flat-ended cylindrical pillar protruding from one end, was connected to the hydraulic test machine and was made from carburised UNS G86200 steel. The diameter of the impacting surface was $6 \mathrm{~mm}$.

The tests were conducted on coupons with dimensions of $38 \mathrm{~mm}$ diameter and $17 \mathrm{~mm}$ thickness. The test samples were located in a sample holder which contained a slurry guard. A constant supply of slurry (freshwater and silica sand) was fed between the impactor and test sample to replicate the "crushing" effect of the sand particles. The stroke between each cycle was $2 \mathrm{~mm}$. The hardness of the impactor tip was $720 \mathrm{HV}$. The silica sand particles were spherical in shape, had an average size of $500 \mu \mathrm{m}$ and a hardness of $1160 \mathrm{HV}$. The sand concentration of the slurry was $54 \mathrm{~g} / \mathrm{l}$. The sand size distribution was measured by sieving the sand incrementally by way of fine sieves; the sand size distribution is given in Table 1.

In order to assess the shape of the silica sand, several images of the sand particles were taken on the Olympus GX-51 light optical microscope at $\times 50$ magnification (Fig. 1). ImageJ image processing software was used to measure the area (A) and perimeter $(\mathrm{P})$ of the sand particles. These values could then be used to calculate the circularity factor (CF) of the sand particles (Eq. 1).

Table 1 Particle size distribution of spherical silica sand

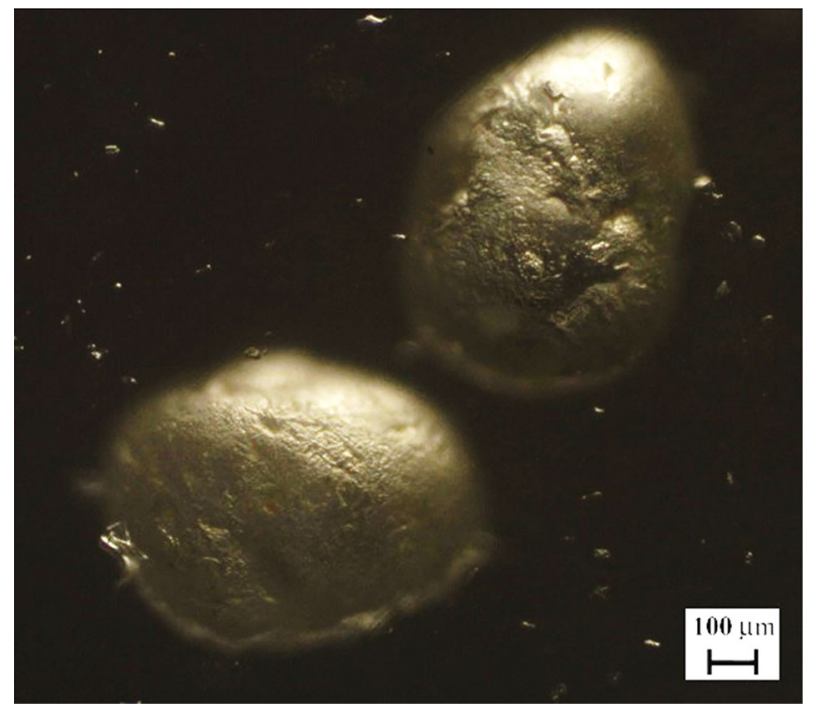

Fig. 1 Silica sand used for repetitive impact with slurry testing

$C F=\frac{4 \pi A}{P^{2}}$

One hundred untested silica sand particles were analysed using this technique to assess the average shape of the particles. Figure 2 demonstrates the amount of sand particles found to have $\mathrm{CF}$ values below 0.8 , between 0.8 and 0.9 and above 0.9. A schematic representation of the defined CF shapes of particles ranging from $0.5-0.95$ is also shown in Fig. 2. The majority of the sand particles were observed to exhibit a CF value above 0.8 .

The slurry was fed between the impactor and sample through a Verderflex peristaltic pump. Once there was a constant flow of slurry, the hydraulic piston was activated which impacted with the sample and crushed the sand at a rate of $5 \mathrm{~Hz}$. The used slurry was then drained from the sample holder which was fed through a second Verderflex peristaltic pump. A schematic diagram and image of the test rig is shown in Fig. 3. A minimum of two test replicates, per test condition was assessed.

Post-test analysis of the resulting wear scars was conducted using an Alicona InfiniteFocus 3D optical profilometer with a wear scar volume accuracy of \pm 0.02 $\mathrm{mm}^{3}$ and a wear scar depth accuracy of $\pm 1 \mu \mathrm{m}$. An initial study demonstrated that mass losses were measurable in some materials but negligible in others. Whereas, the volume measurements facilitated more realistic comparisons between the different materials and such volume measurements were correlated with the damage mechanisms. Cross sections of the wear scars were taken using a Struers Discotom-2 abrasive cutting machine, mounted in Bakelite and polished to $0.05 \mu \mathrm{m}$ finish. The cross 
Fig. 2 Circularity factors for 100 untested silica sand particles
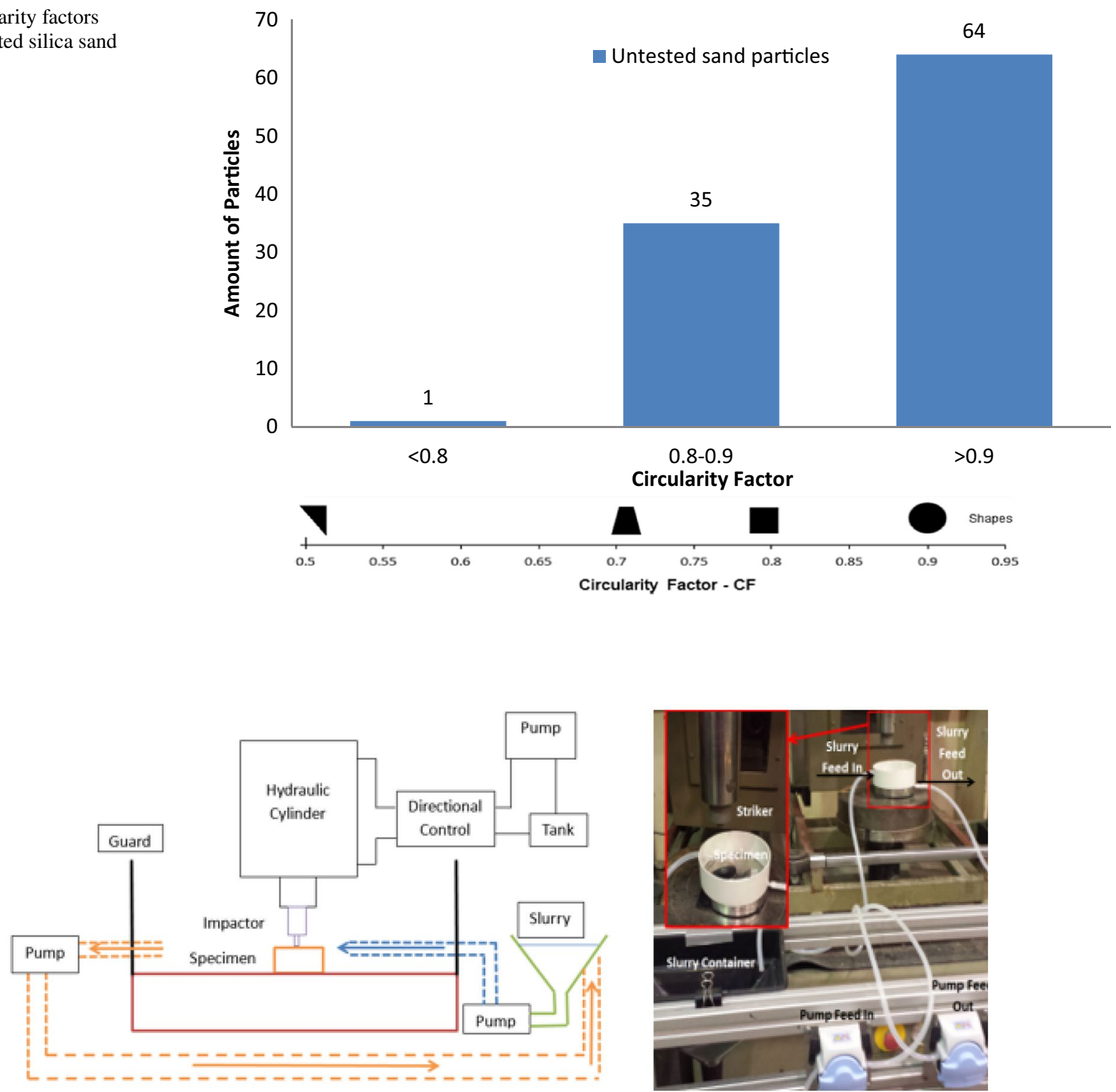

Fig. 3 Schematic diagram and image of the repetitive impact with slurry test rig

sections of the damaged surfaces were then assessed using Scanning Electron Microscopy (SEM - Hitachi SU-6600) with a $20 \mathrm{kV}$ accelerating voltage and secondary electron detector. Microhardness profiles were measured using a Mitutoyo MVK-G1 test machine with a $200 \mathrm{gf}$ load.

\subsection{Materials}

In order to obtain correlation between repetitive impact behaviour and material type, a wide range of materials was assessed. The materials which were examined are shown in Table 2.

\section{Results and Discussion}

\section{1 "Crushing" Effect of Sand}

Preliminary testing was conducted to assess the contribution of damage from the "crushing" effect of the sand. In order to evaluate this, tests were conducted with and without slurry. The material used in these initial tests was UNS S31600. Figure 4 shows the appearance of the UNS S31600 test specimen after the exposure to repetitive impact without slurry along with the corresponding $3 \mathrm{D}$ surface topography scan and wear scar profile. A 
Table 2 List of materials in test programme

\begin{tabular}{|c|c|c|c|}
\hline Material Types & Grades/descriptions & Major alloying elements (wt.\%) & Microstructure \\
\hline \multirow[t]{5}{*}{ Heat treated steels } & Carburised UNS G86200 & $0.2 \% \mathrm{C}, 0.5 \mathrm{Cr}, 0.5 \mathrm{Ni}, 0.8 \mathrm{Mn}, \mathrm{Bal} . \mathrm{Fe}$ & $\begin{array}{l}\text { Martensitic with case hardened depth of } \\
1.2 \mathrm{~mm}\end{array}$ \\
\hline & Induction hardened UNS G52986 & $1 \% \mathrm{C}, 1.4 \% \mathrm{Cr}, 0.3 \% \mathrm{Mn}, \mathrm{Bal} . \mathrm{Fe}$ & Martensitic with hardened depth of $8 \mathrm{~mm}$ \\
\hline & Induction hardened UNS G41400 & $\begin{array}{l}0.4 \% \mathrm{C}, 1 \% \mathrm{Cr}, 0.5 \% \mathrm{Mo}, 0.85 \% \mathrm{Mn} \text {, } \\
\text { Bal. Fe }\end{array}$ & $\begin{array}{l}\text { Martensitic with hardened depth of } \\
5.5 \mathrm{~mm}\end{array}$ \\
\hline & Quenched \& tempered UNS G52986 & $1 \% \mathrm{C}, 1.4 \% \mathrm{Cr}, 0.3 \% \mathrm{Mn}, \mathrm{Bal} . \mathrm{Fe}$ & Martensitic \\
\hline & Nitrided 905M39 & $\begin{array}{l}0.4 \% \mathrm{C}, 1.6 \% \mathrm{Cr}, 0.2 \% \mathrm{Mo}, 0.5 \% \mathrm{Mn} \text {, } \\
\text { Bal. Fe }\end{array}$ & White hard layer with depth of $0.25 \mathrm{~mm}$ \\
\hline \multirow[t]{6}{*}{ Stainless steels } & UNS S31600 & $17 \% \mathrm{Cr}, 12 \% \mathrm{~N}, 2 \% \mathrm{Mo}$, Bal. Fe & Austenitic \\
\hline & UNS S42000 & $13 \% \mathrm{Cr},<1 \% \mathrm{Mn},<1 \% \mathrm{Si}$, Bal. Fe & Martensitic \\
\hline & UNS S44003 & $0.8 \% \mathrm{C}, 17 \% \mathrm{Cr}, \mathrm{Bal} . \mathrm{Fe}$ & Martensitic \\
\hline & UNS S44004 & 1\%C, 17\%Cr, Bal. Fe & Martensitic \\
\hline & UNS S15500 & $15 \% \mathrm{Cr}, 4 \% \mathrm{Ni}, 3 \% \mathrm{Cu}$, Bal. Fe & Martensitic with precipitates \\
\hline & UNS S32760 & $25 \% \mathrm{Cr}, 7 \% \mathrm{Ni}, 3 \% \mathrm{Mo}, \mathrm{Bal} . \mathrm{Fe}$ & $50 \%$ ferrite $/ 50 \%$ austenite \\
\hline \multirow[t]{2}{*}{ Superalloys } & UNS N07718 & $20 \% \mathrm{Cr}, 19 \% \mathrm{Fe}, \mathrm{Bal} . \mathrm{Ni}$ & $\gamma$ austenite with precipitates \\
\hline & UNS R56400 & $6 \% \mathrm{Al}, 4 \% \mathrm{~V}, \mathrm{Bal} . \mathrm{Ti}$ & Alpha+Beta \\
\hline \multirow[t]{2}{*}{ Chromium cast irons } & $27 \% \mathrm{Cr}$ cast iron & $3 \% \mathrm{C}, 27 \% \mathrm{Cr}, \mathrm{Bal} . \mathrm{Fe}$ & $\begin{array}{l}\text { Hypoeutectic } \mathrm{Cr} \text { cast iron with martensi- } \\
\text { tic metal matrix and } \mathrm{M}_{7} \mathrm{C}_{3} \text { carbides }\end{array}$ \\
\hline & $37 \% \mathrm{Cr}$ cast iron & $2 \% \mathrm{C}, 37 \% \mathrm{Cr}, \mathrm{Bal} . \mathrm{Fe}$ & $\begin{array}{l}\text { Hypoeutectic } \mathrm{Cr} \text { cast iron with austenitic } \\
\text { metal matrix and } \mathrm{M}_{7} \mathrm{C}_{3} \text { carbides }\end{array}$ \\
\hline \multirow[t]{2}{*}{ Hardfacing coatings } & Stellite 6 weld cladding & $24 \% \mathrm{Cr}, 18 \% \mathrm{Fe}, 4 \% \mathrm{~W}, 0.9 \% \mathrm{C}$, Bal. Co & $\begin{array}{l}\text { Co-rich matrix with Cr-rich carbides } \\
\text { coating depth of } 3 \mathrm{~mm} \\
\text { Nitrided version }-27 \mu \mathrm{m} \text { thick nitride } \\
\text { compound layer }\end{array}$ \\
\hline & HVOF 90WC-10Ni & $90 \% \mathrm{~W}, 10 \% \mathrm{Ni}$ & $\begin{array}{l}\text { Tungsten carbide in nickel matrix, coat- } \\
\text { ing depth of } 500 \mu \mathrm{m}\end{array}$ \\
\hline
\end{tabular}

reasonably uniform wear scar profile was observed. Negligible mass loss measurements were observed, indicating that the damage was associated with plastic deformation. The wear scar depths and volume losses for the tests are shown in Figs. 5 and 6.

Wear scar depths and volume losses both increased when sand particles were being crushed between the impactor and specimen demonstrating that the crushing of the sand particles contributes to the repetitive impact damage (20-50\% of overall damage). However, it should be noted that a significant amount of the damage was attributed to only repetitiveimpact wear (without slurry).

\subsection{Surface Topography of Tested Materials under Slurry Conditions}

\subsubsection{Wear Scar Depths}

The wear scar depths for all tested materials are shown in Fig. 7. The scatter bands represent the variation between two test replicates. The UNS S31600 stainless steel and HVOF WC-10Ni exhibited the greatest wear scar depths of all test materials whereas, the carburised UNS G86200 and 27\% Cr cast iron demonstrated the lowest wear scar depths. In general, materials with a martensitic microstructure (carburised UNS G86200, 27\% Cr cast iron, UNS S42000 (480HV), induction hardened UNS G52986, etc.) had lower wear scar depths than materials with an austenitic microstructure (UNS S31600 and 37\% Cr cast iron). This observation has been perceived in previous studies $[15,31]$. However, there were exceptions to this as the UNS S42000 (280 HV), UNS S44003 and UNS S44004 all demonstrated wear scar depths greater than the $37 \% \mathrm{Cr}$ cast iron (dual phase - austenite with chromium carbides) and UNS S32760 (dual phase - austenite and ferrite). The reason for this discrepancy is likely to be associated with the fact that the three martensitic materials were in the annealed condition. It is also interesting to note that by modifying the austenitic structure to obtain greater strength (i.e. through addition of chromium carbides or ferrite) then it is possible to improve their repetitive impact resistance.

\subsubsection{Wear Scar Volume Loss}

The wear scar volume losses for all test materials are given in Fig. 8, materials with a volume loss with less than 0.2 $\mathrm{mm}^{3}$ are also presented in Fig. 9 for a better comparison. A similar trend to those found with wear scar depths was 


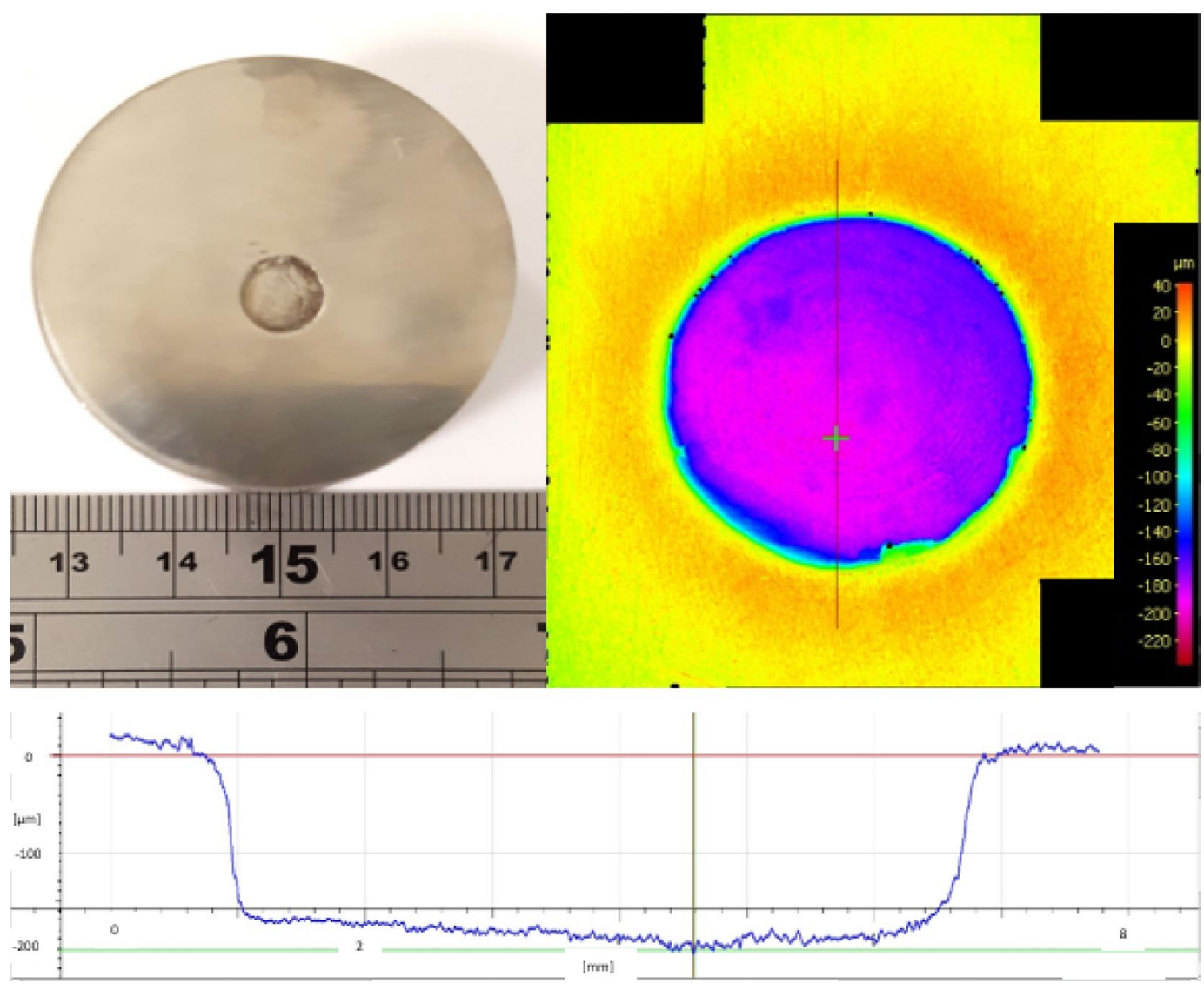

Fig. 4 Image of UNS S31600 without slurry after test (top left); 3D surface topography scan (top right); wear scar profile (bottom)

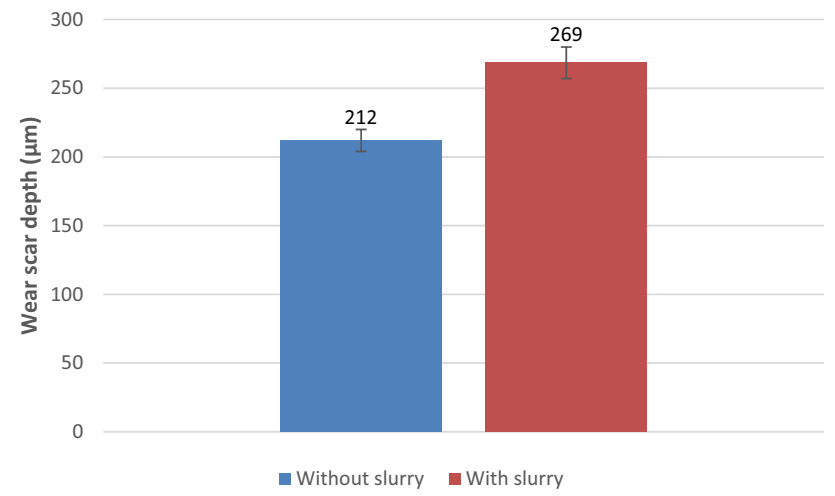

Fig. 5 Wear scar depth for UNS S31600 with and without slurry

observed, as the UNS S31600 stainless steel and HVOF WC-10Ni exhibited the greatest wear scar volume losses and the carburised UNS G86200 and $27 \% \mathrm{Cr}$ cast iron demonstrated the lowest wear scar volume losses. This correspondence between scar depth and volume confirms that the wear scar depths are not dominated by localised penetrations.

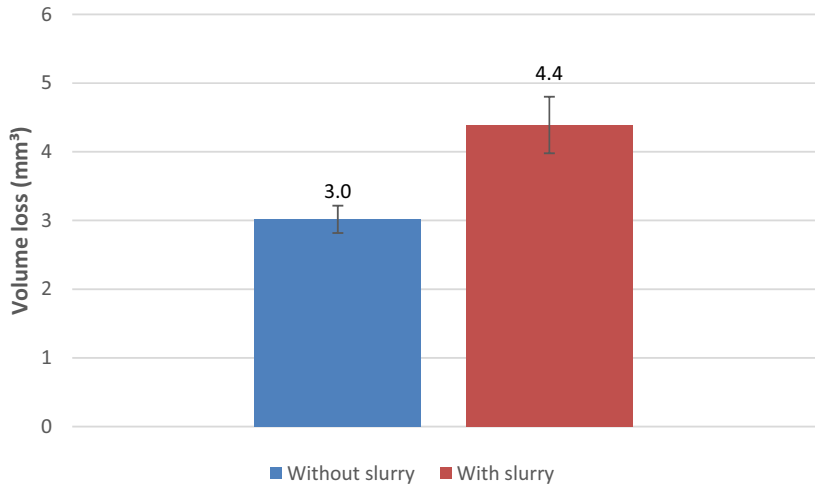

Fig. 6 Volume losses for the UNS S31600 with and without slurry

\subsubsection{Wear Mechanisms Occurring in Repetitively Impacted Zones}

The material degradation mechanisms occurring inside the repetitively impacted wear scars were examined through SEM images of cross sectioned wear regions. A light microscope was used for an in-plane image of the HVOF WC10Ni coating wear scar (Fig. 23). A micro hardness profile 
Fig. 7 Wear scar depths for the tested materials

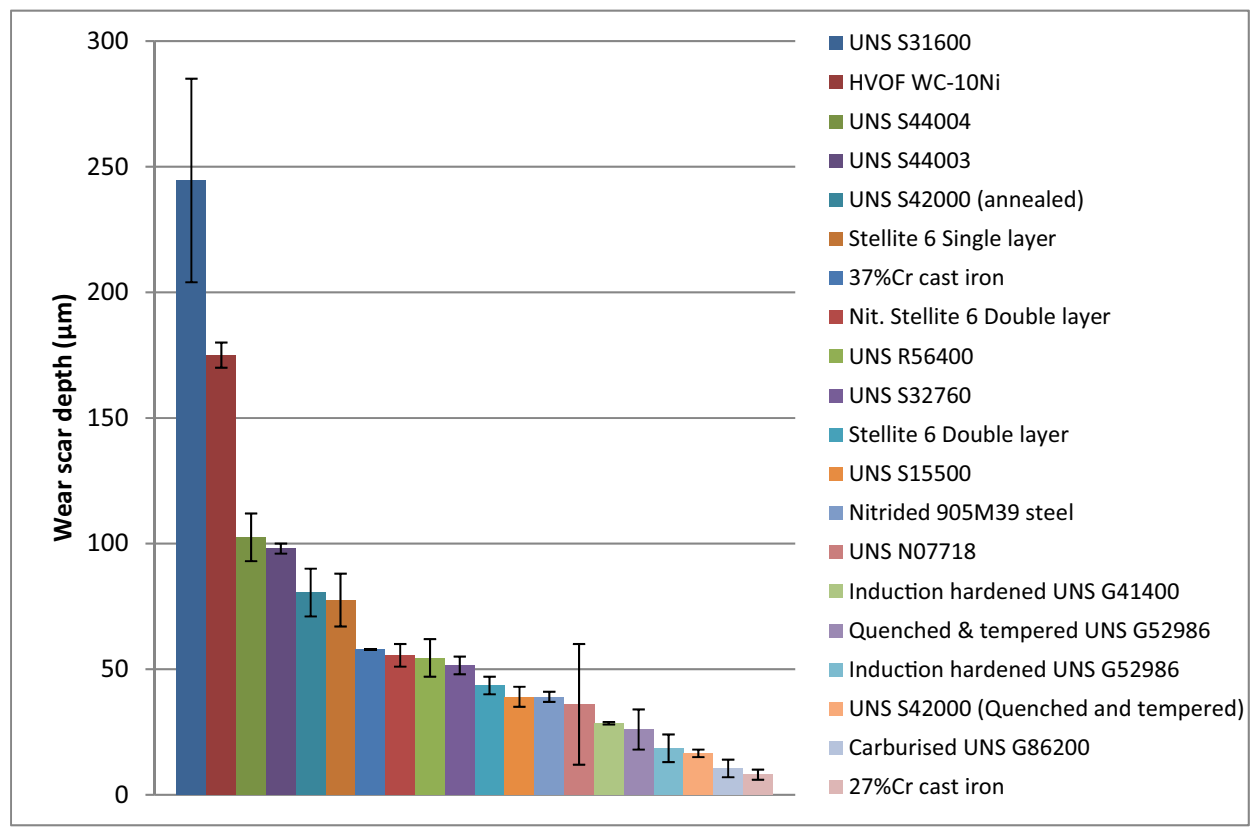

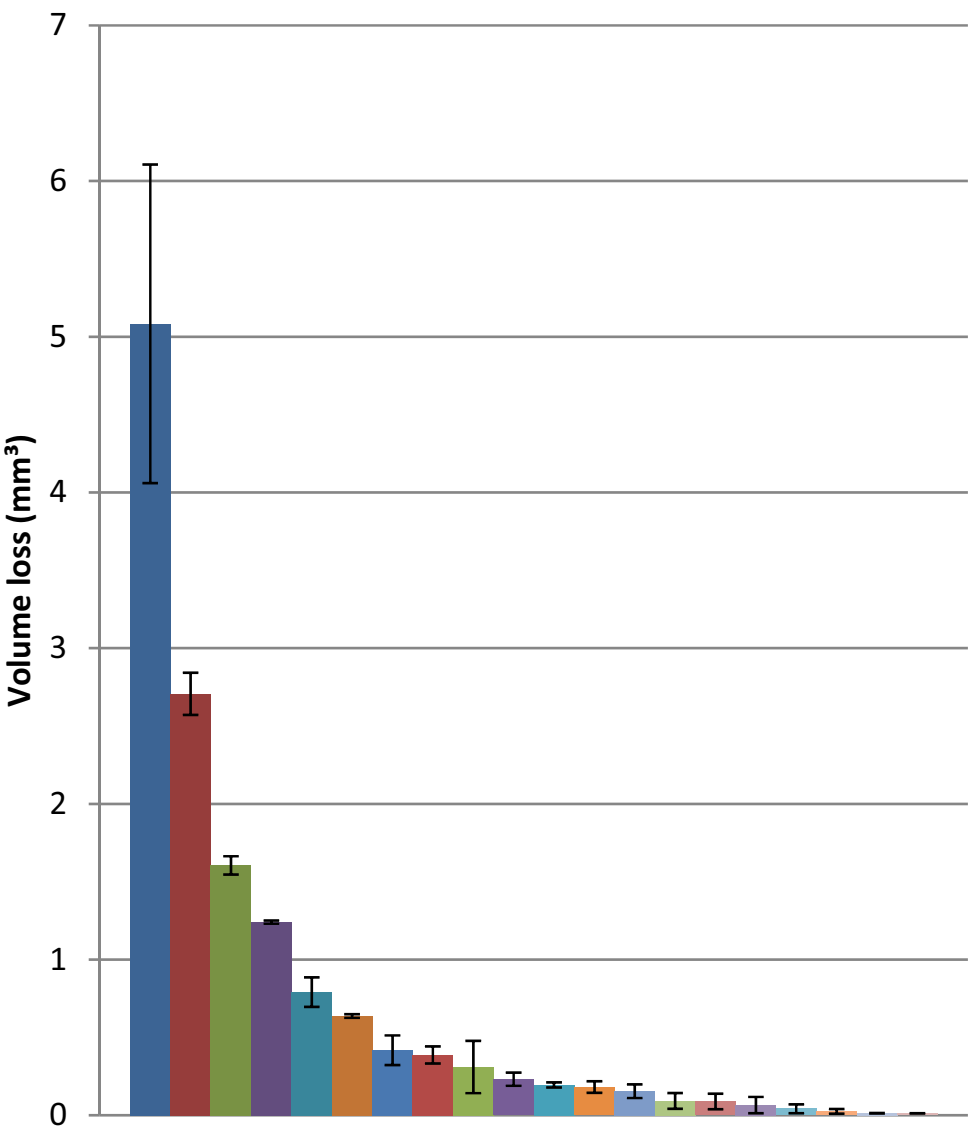

UNS S31600

HVOF WC-10Ni

UNS 544004

- UNS S44003

- Stellite 6 Single layer

- UNS S32760

- Stellite 6 Double layer

$37 \% \mathrm{Cr}$ cast iron

- UNS S42000 (annealed)

nitrided 905M39 steel

Nit. Stellite 6 Double layer

UNS $\$ 15500$

- UNS R56400

- Induction hardened UNS G41400

UNS N07718

- Induction hardened UNS G52986

- Quenched \& tempered UNS G52986

$27 \% \mathrm{Cr}$ cast iron

- UNS S42000 (Quenched and tempered)

Carburised UNS G86200

Fig. 8 Wear scar volume losses for the tested materials 
Fig. 9 Wear scar volume losses (less than $0.2 \mathrm{~mm}^{3}$ ) for the tested materials

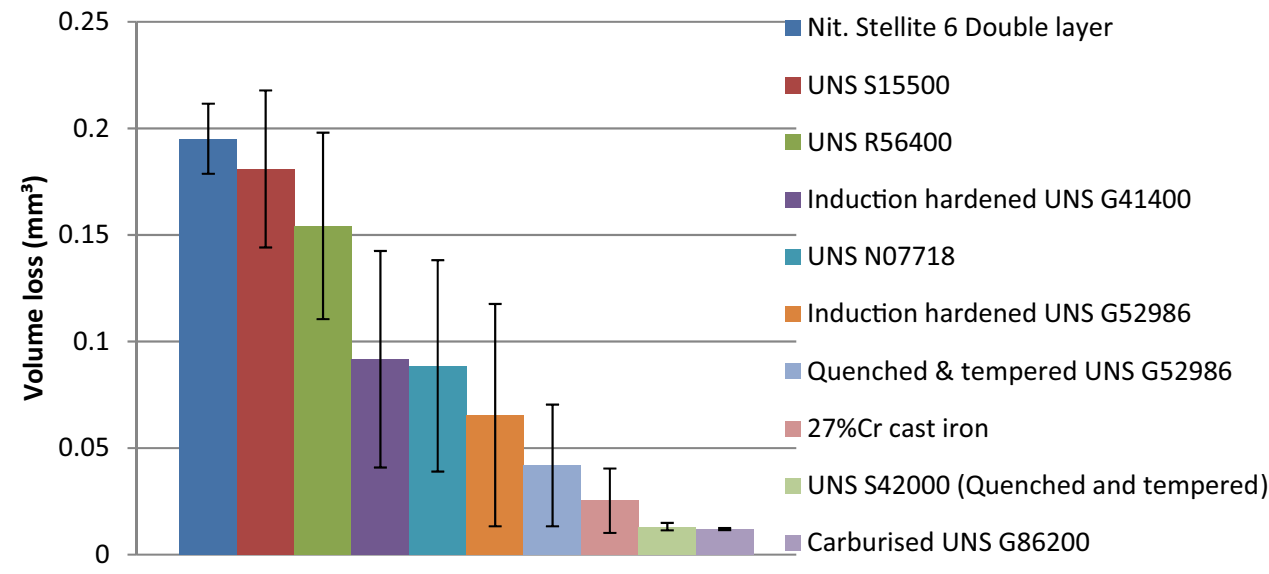

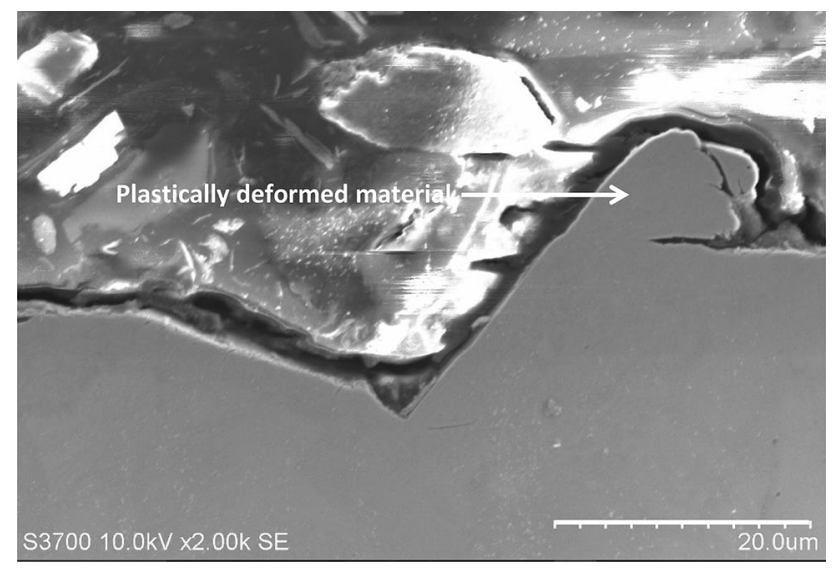

Fig. 10 Plastically deformed material in UNS S31600 wear scar following impact wear testing

for the ductile materials was also conducted to assess work hardening effects. A selection of ductile and hard/brittle materials (listed below) were chosen to be analysed.

- Ductile materials (200 HV-285 HV) - UNS S31600, UNS S42000 (annealed - 280 HV), UNS S44003 (annealed - $285 \mathrm{HV}$ ), UNS S32760

- Hard/brittle materials (720 HV-1100 HV) - 27\% Cr cast iron, carburised UNS G86200, Nitrided 905M39 Steel, HVOF WC-10Ni

\subsection{Ductile Materials}

\subsubsection{UNS S31600 (200HV)}

The main material degradation mechanism for the UNS S31600 was plastic deformation where regions within the wear scar suffered from a cutting/shearing effect from "crushing" sand particles (Fig. 10). This type of damage is similar to cutting deformation wear as described by Hutchings [47], who stated that subsequent impacts will easily

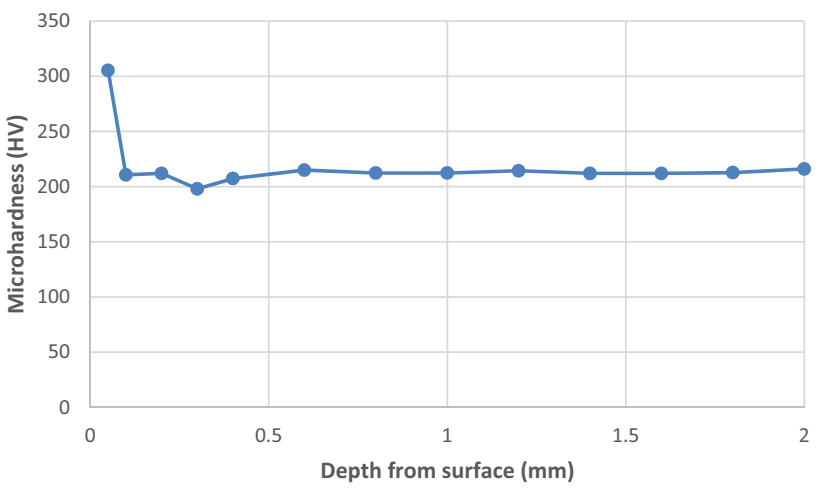

Fig. 11 Micro hardness profile for UNS S31600 wear scar

remove the vulnerable material displaced in the highly strained lip. Work by Ratia et al. attributed large amounts of plastic deformation of materials with low hardness and high ductility [37].

A hardness increase of $100 \mathrm{HV}$ was observed at the surface of the UNS S31600 impact wear scar (Fig. 11). This strain hardening effect of UNS S31600 has been observed previously by a number of researchers [48-50]. Singh et al. conducted air blasting experiments at normal incidence and found that the surface hardness of UNS S31600 increased from 160 to 430 HV [49]. Similarly, Giourntas observed hardness increases of $100 \mathrm{HK}$ (Knoop hardness) in a wear scar of UNS S31600 after an impinging slurry jet experiment [50]. Work hardening effects have also been observed in wear-resistant steels under impact-abrasion conditions [41, 42].

\subsubsection{UNS S42000 (280 HV)}

For UNS S42000, the main degradation mechanism was found to be micro-ploughing which has resulted in plastically deformed material (Fig. 12). Localised regions in the wear scar exhibited heavily sheared material which is vulnerable to removal in subsequent impacts. No increase 


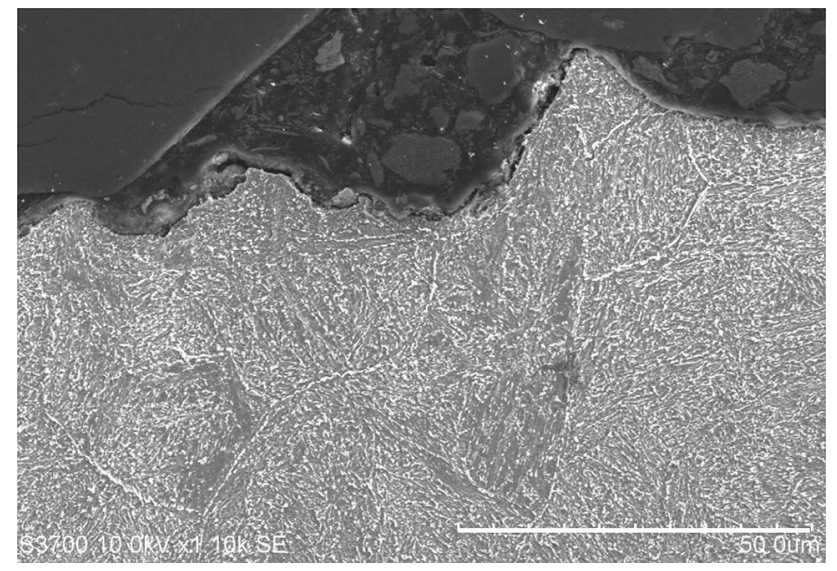

Fig. 12 Plastically deformed material in UNS S42000 (280 HV) wear scar

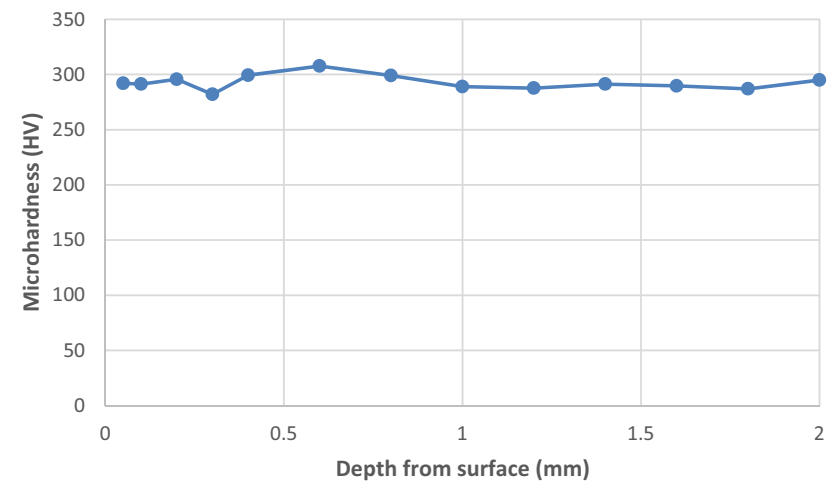

Fig. 13 Micro hardness profile for UNS S42000 (280 HV) wear scar

in surface hardness was observed for the UNS S42000 (Fig. 13).

\subsubsection{UNS S44003 (285HV)}

The UNS S44003 specimens exhibited two different types of wear damage. Figure 14 illustrates the cross section of the UNS S44003, where subsurface cracking was observed on a primary carbide. This feature illustrates that impact stresses, caused by the impactor and "crushed" sand particles, have transferred onto the carbides which has resulted in cracking. It is possible that the fractured carbides underneath the surface will increase the likelihood of spalling which has then caused material to be removed (Fig. 15). It is also possible that martensite has also deformed and the combination of these degradation processes has led to the removal of material. No increase in hardness was observed for the UNS S44003 (Fig. 16). The different deterioration mechanisms observed

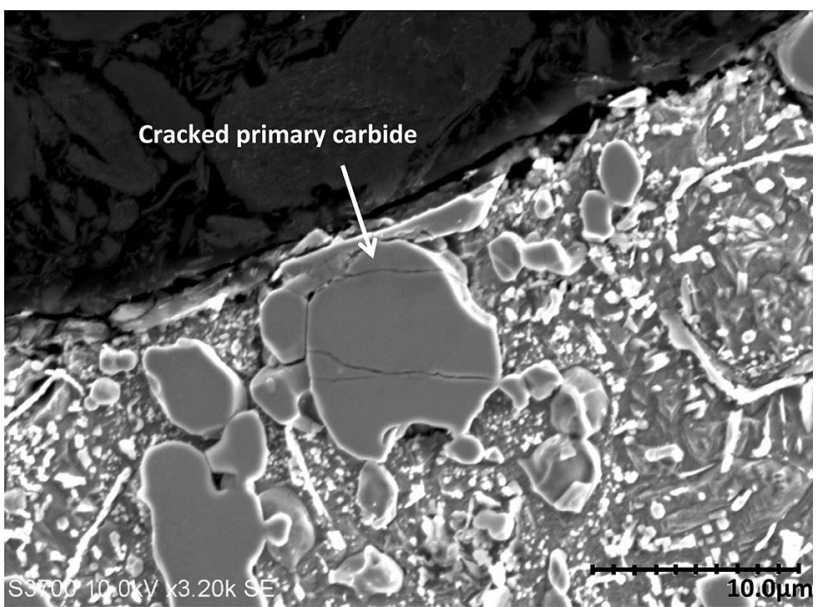

Fig. 14 Cracked primary carbide in UNS S44003 wear scar

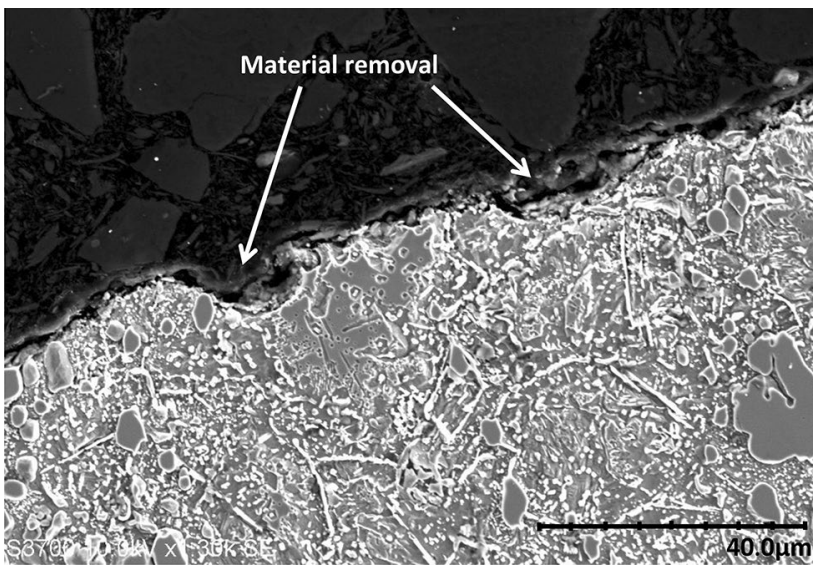

Fig. 15 Material removal in UNS S44003 wear scar

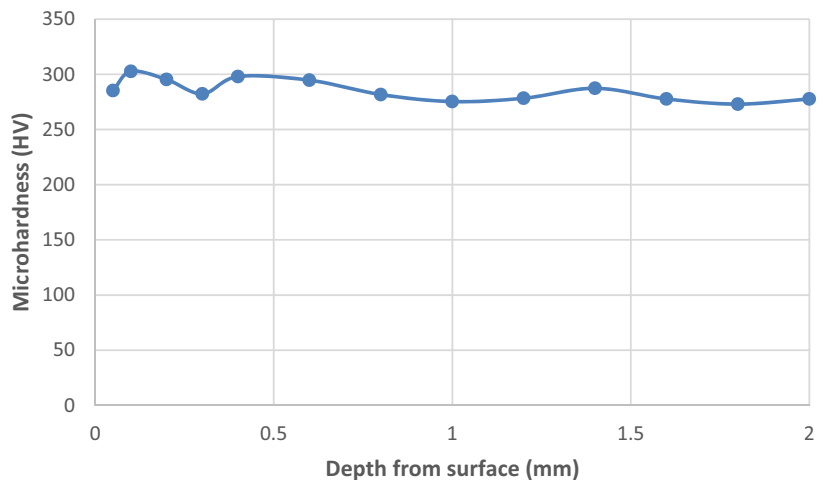

Fig. 16 Micro hardness profile for UNS S44003 wear scar 


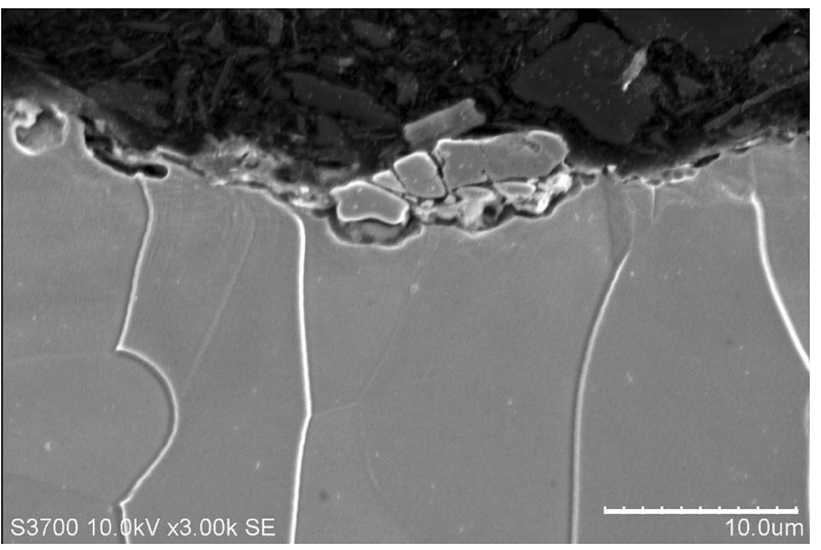

Fig. 17 Sections of grain being removed in UNS S32760 wear scar

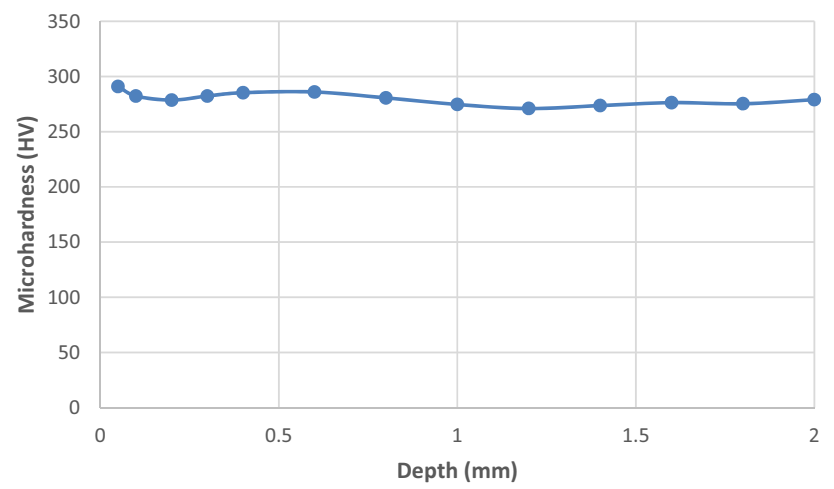

Fig. 18 Micro hardness profile for UNS S32760 wear scar

between UNS S42000 and UNS S44003 highlight how materials with similar hardnesses can experience different wear processes.

\subsubsection{Superduplex Stainless Steel—UNS S32760 (280 HV)}

Figure 17 shows the cross section of UNS S32760 wear scar, where sections of grains have been removed. The removal of these grain sections is likely to be attributed to surface fatigue caused by the high stresses applied by the repetitive "crushing" of sand particles into the surface of the material. This phase is likely to be the ferrite due to the greater strain rate sensitivity of its BCC lattice structure. The brittle fracture-nature of ferrite has previously been observed [51]. No increase in surface hardness was observed for UNS S32760 (Fig. 18).

\subsection{Hard Materials}

\subsubsection{7\% Cr Cast Iron}

The $27 \% \mathrm{Cr}$ cast iron exhibited a similar type of degradation processes as the UNS S44003. In localised regions within

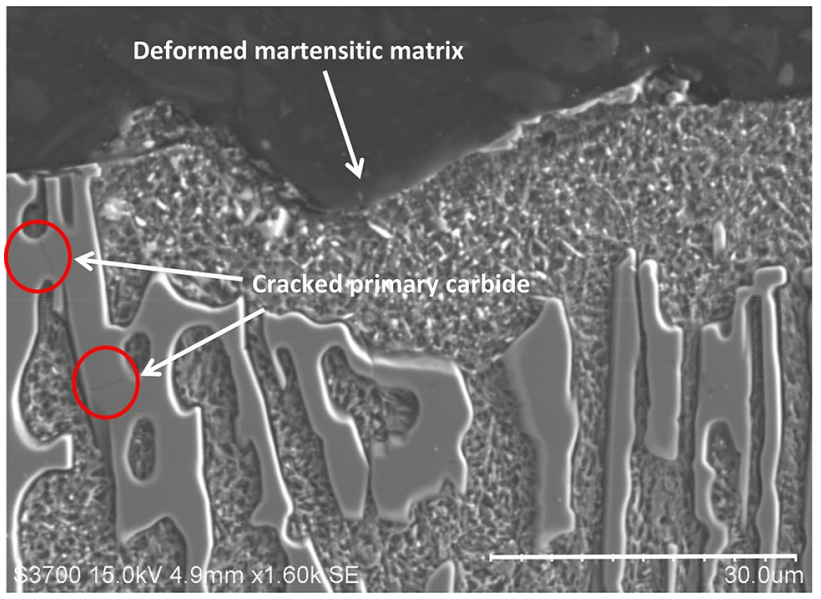

Fig. 19 Deformed martensitic matrix and cracked primary carbide in $27 \% \mathrm{Cr}$ cast iron wear scar

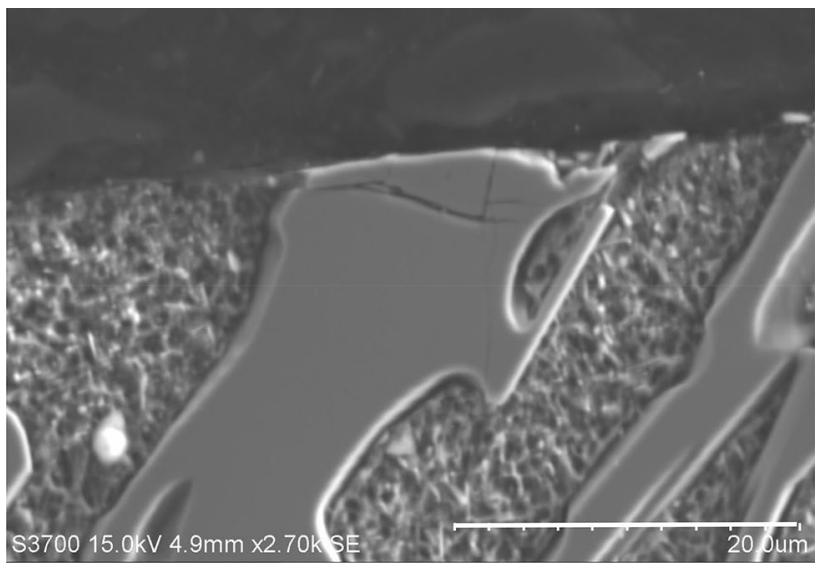

Fig. 20 Cracking in primary carbide in $27 \% \mathrm{Cr}$ cast iron wear scar

the wear scar, the martensitic matrix was heavily deformed (Fig. 19) and cracks were observed in primary carbides (Figs. 19 and 20). This has been caused by the high impact stresses from "crushed" sand particles. Qian et al. [46] have also observed that the effect of repetitive impact loading on a white cast iron resulted in severe fragmentation of primary and eutectic carbides together with micro-cracking along the eutectic carbide network.

\subsubsection{Carburised UNS G86200}

The carburised UNS G86200 exhibited subsurface cracks, caused by the high impact stresses associated with the repetitive impact testing. Cracks were observed to occur parallel and perpendicular to the surface which leads to material being spalled and/or delaminated from the surface of the carburised UNS G86200 steel (Fig. 21). Subsurface cracking caused by repetitive impact wear has previously been 


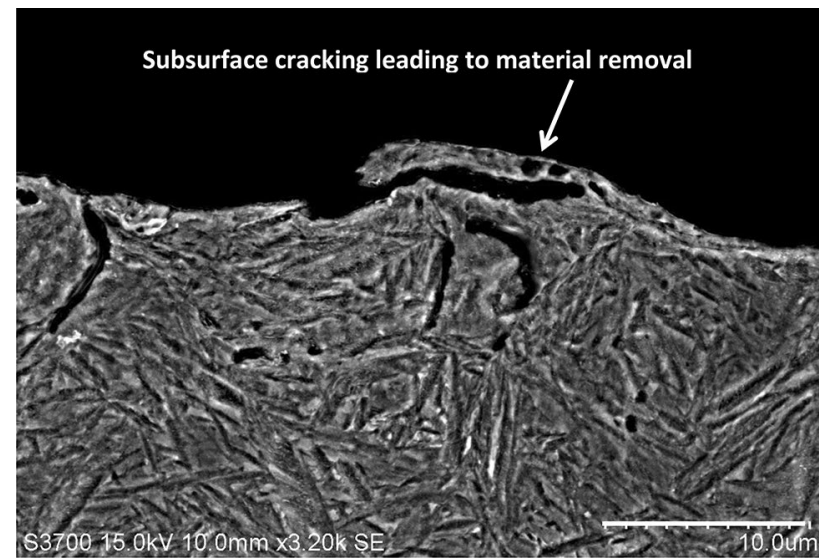

Fig. 21 Subsurface cracking leading to material removal in carburised UNS G86200 wear scar

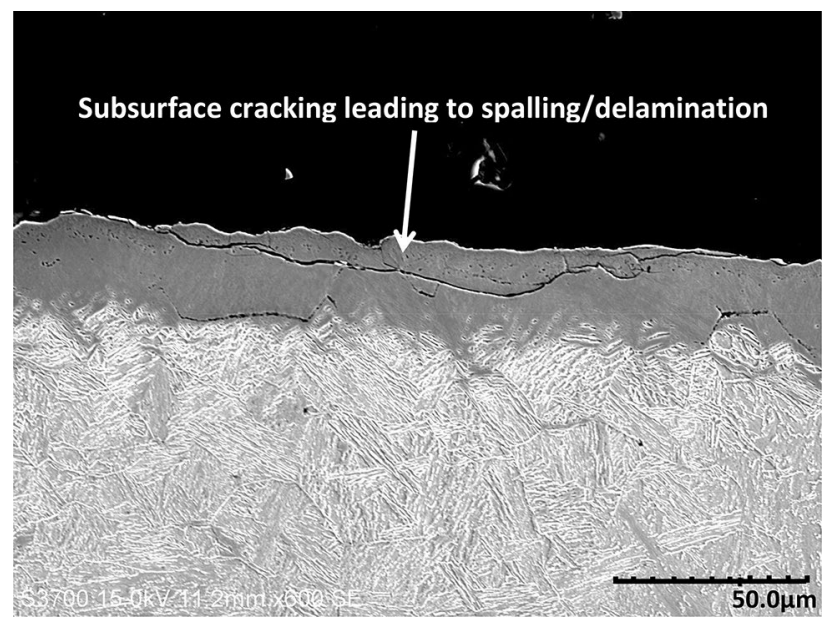

Fig. 22 Subsurface cracking leading to material removal in nitrided 905M39 steel wear scar

observed by various researchers on different steel grades and PVD coatings $[6,20,30,36]$.

\subsubsection{Nitrided 905M39 Steel}

The nitrided 905M39 steel also exhibited an extensive network of subsurface cracks which extend over $100 \mu \mathrm{m}$ in length (Fig. 22). The vast crack network eventually results in delamination and spalling of the nitride layer. Similar severe cracking on the nitrided layer was observed on the nitrided Stellite 6 weld cladding.

\subsubsection{HVOF WC-10Ni}

Figure 23 demonstrates abundant cracking occurring at the surface and sub-surface of the HVOF WC-Ni coating. The cracking shown on Fig. 22 for the nitrided 905M39 steel is observed to be similar for the HVOF WC-Ni coating and the cracks were even evident on the surface, as shown in Fig. 23. Cracks were observed within the wear scar and also circumferentially outside the wear scar. Sub-surface cracks were found to run horizontally throughout the coating, especially near the coating-substrate interface (Fig. 23b, c and d). At the edge of the wear scar, a large piece of coating was observed to be almost detached from the coating (Figs. 23b and c). Due to the hard/brittle-nature of the coating, material was removed by spalling and delamination.

3.4.4.1 Relationship with Material Properties An assessment was conducted to establish relationships, if any, between repetitive impact resistance and material properties. The material properties which were used for the assessment were hardness, elastic modulus and fracture toughness. Figure 24 demonstrates the relationship between material hardness and repetitive impact wear scar depth. In general terms, as the hardness increases (from $200 \mathrm{HV}$ ) the wear scar depth decreases up to a hardness of approximately $765 \mathrm{HV}$. Above this hardness value the wear scar depths increases. Although this trend might be construed to indicate that there is an optimum hardness where repetitive impact wear is at a minimum, the general consensus is that hardness alone is insufficient to correlate with repetitive impact wear resistance $[52,53]$.

Figure 25 exhibits the relationship between the hardness/ elastic modulus (H/E) ratio [54] with the repetitive impact wear scar depth. In general, there was a reduction in wear scar depth as the $\mathrm{H} / \mathrm{E}$ ratio increased. However, there was no direct correlation which could be used to predict the behaviour of a material under repetitive impact conditions.

Another material property which, together with hardness, is likely to be crucial to the repetitive impact wear resistance of a material is fracture toughness. Chintha et al. [52] have shown that, under impact-abrasion conditions, steels with similar hardness, composition and microstructural phases but different fracture toughness behave differently with the steel of higher toughness demonstrating greater resistance to both impact and abrasive wear. Another study by Liu et al. [53] demonstrated that high $\mathrm{H} / \mathrm{K}_{1 \mathrm{C}}$ (hardness/ fracture toughness ratio) for bainitic steels could improve their impact-abrasion wear resistance up to a point, after which the wear resistance of the steels decreased due to a lower critical stress for crack formation. Figure 26 shows the relationship between wear scar depth and $\mathrm{H} / \mathrm{K}_{1 \mathrm{C}}$ for some of the test materials evaluated in the current study. It can be clearly observed that the minimum wear scar depth occurs approximately around a $\mathrm{H} / \mathrm{K}_{1 \mathrm{C}}$ ratio of 350 . The trend of the graph follows a similar observation made by Liu et al. [53] where there is a point of maximum wear resistance before increasing the $\mathrm{H} / \mathrm{K}_{1 \mathrm{C}}$ ratio further is detrimental to the repetitive impact wear resistance. There is a reasonable 


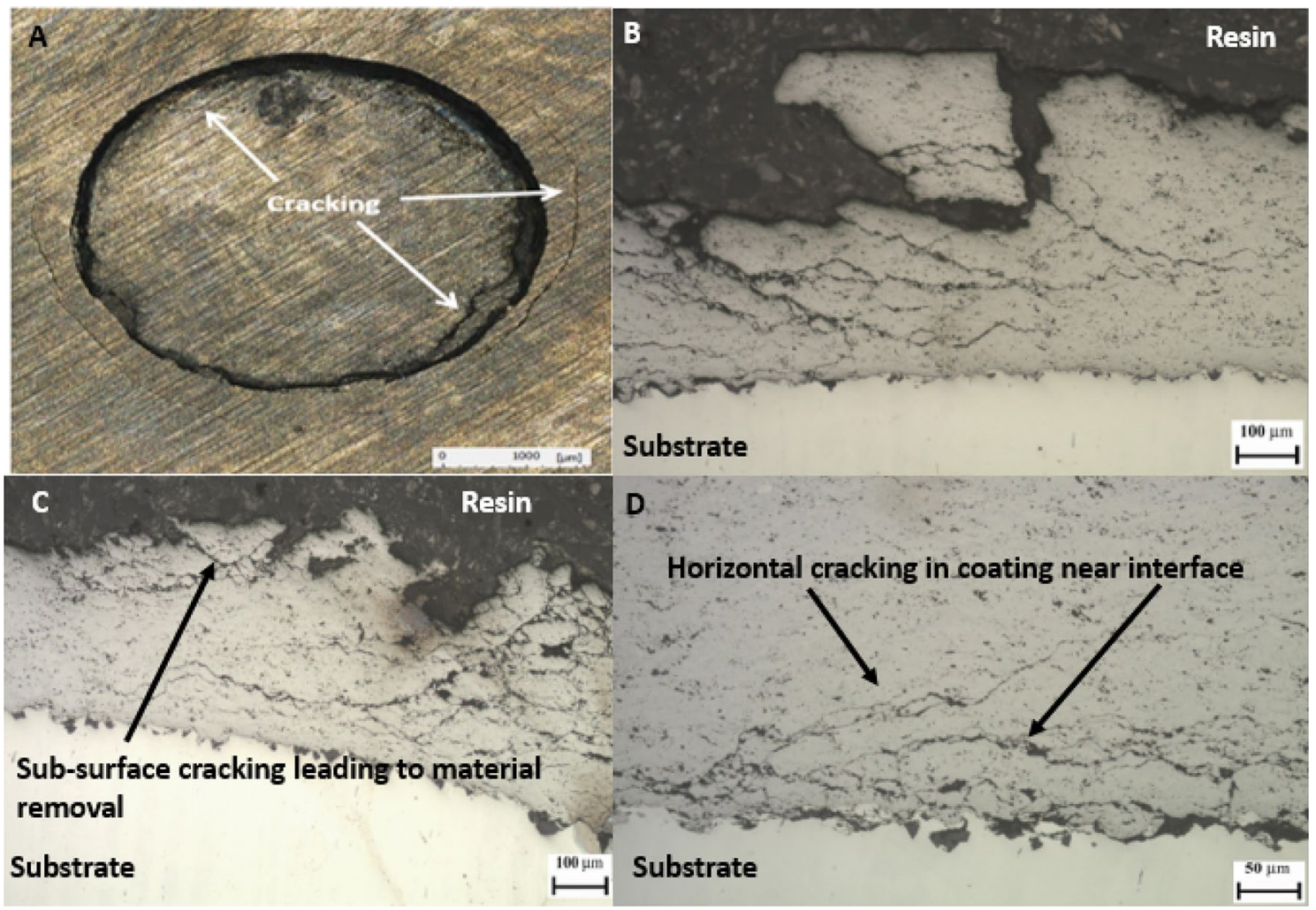

Fig. 23 HVOF WC-Ni; a Circumferential micro-cracking visible inplan view; $\mathbf{b}$ and $\mathbf{c}$ Cross section showing significant amounts of horizontal micro-cracks with large section of material almost removed from coating; d horizontal micro-cracking observed in coating at coating-substrate interface
Fig. 24 Relationship between material hardness and repetitive impact wear scar depths

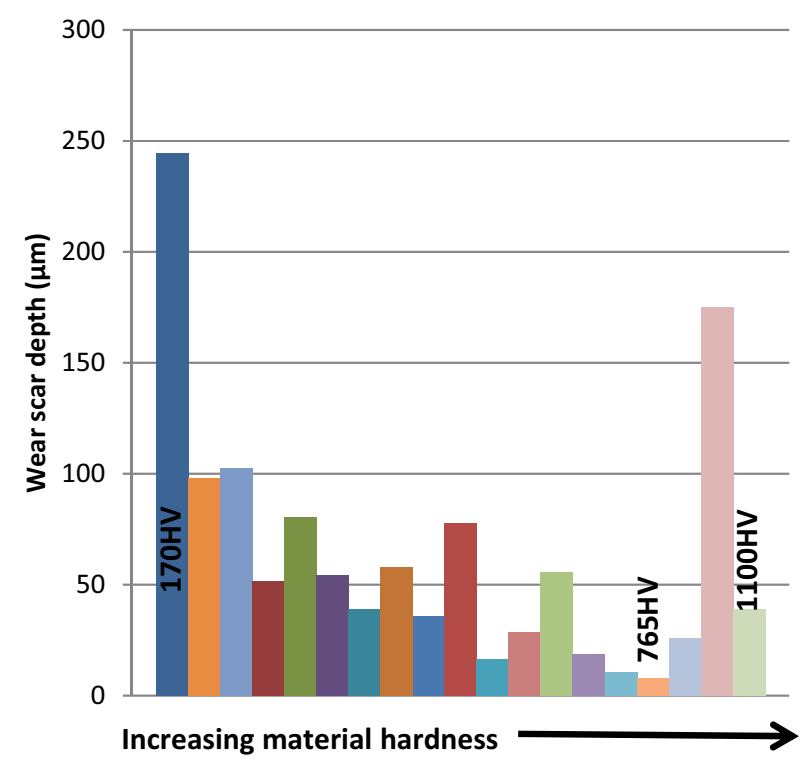

- UNS S31600

UNS $\$ 44003$

- UNS 544004

- UNS $\$ 32760$

- UNS S42000 (280HV)

- UNS R56400

- UNS S15500

-37\% Cr cast iron

- UNS N07718

- Stellite 6 single layer

- UNS S42000 (480HV)

- Induction Hardened UNS G41400

Nit. Stellite 6 Double layer

- Induction Hardened UNS G52986

Carburised UNS G86200

$27 \% \mathrm{Cr}$ cast iron

Quenched \& Tempered UNS G52986

HVOF WC-10Ni

Nitrided 905M39 Steel correlation between the dominant wear mechanism from plastic deformation-induced damage (Figs. 10 and 12) to brittle cracking (Figs. 22 and 23). Where the former is dominant there is a decrease in wear with increasing $\mathrm{H} / \mathrm{K}_{1 \mathrm{C}}$, but, when the dominant damage mode changes to a crackinduced mechanism an opposite trend of $\mathrm{H} / \mathrm{K}_{1 \mathrm{C}}$ prevails. Similar trends have been observed by Liu et al. [53] but restricted to bainitic steel grades. These studies, therefore, 
Fig. 25 Relationship between $\mathrm{H} / \mathrm{E}$ ratio and repetitive impact wear scar depths

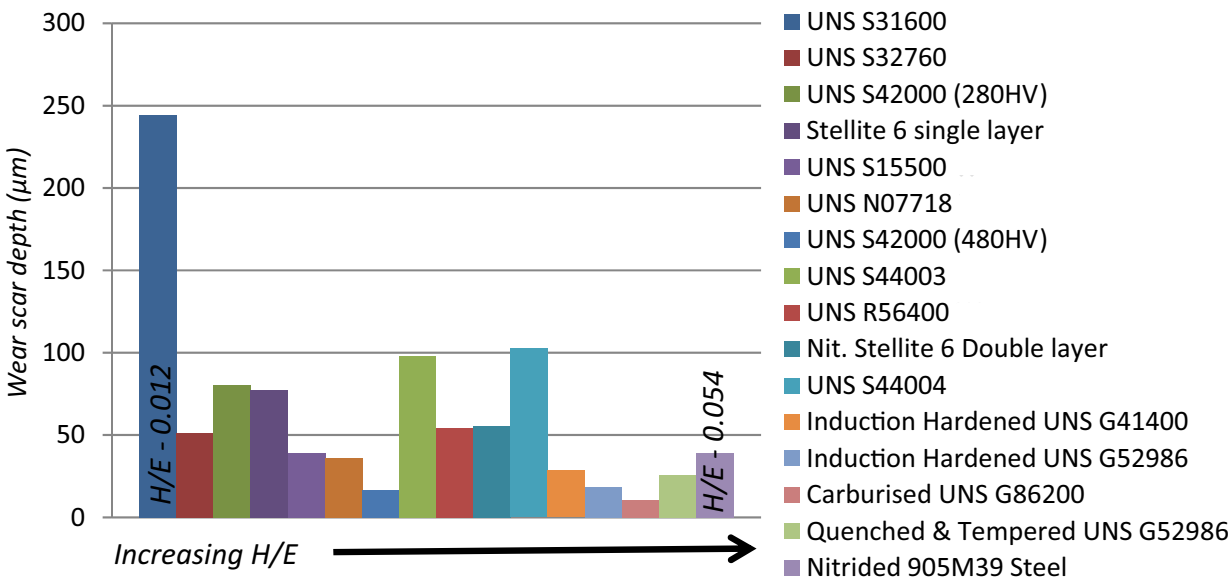

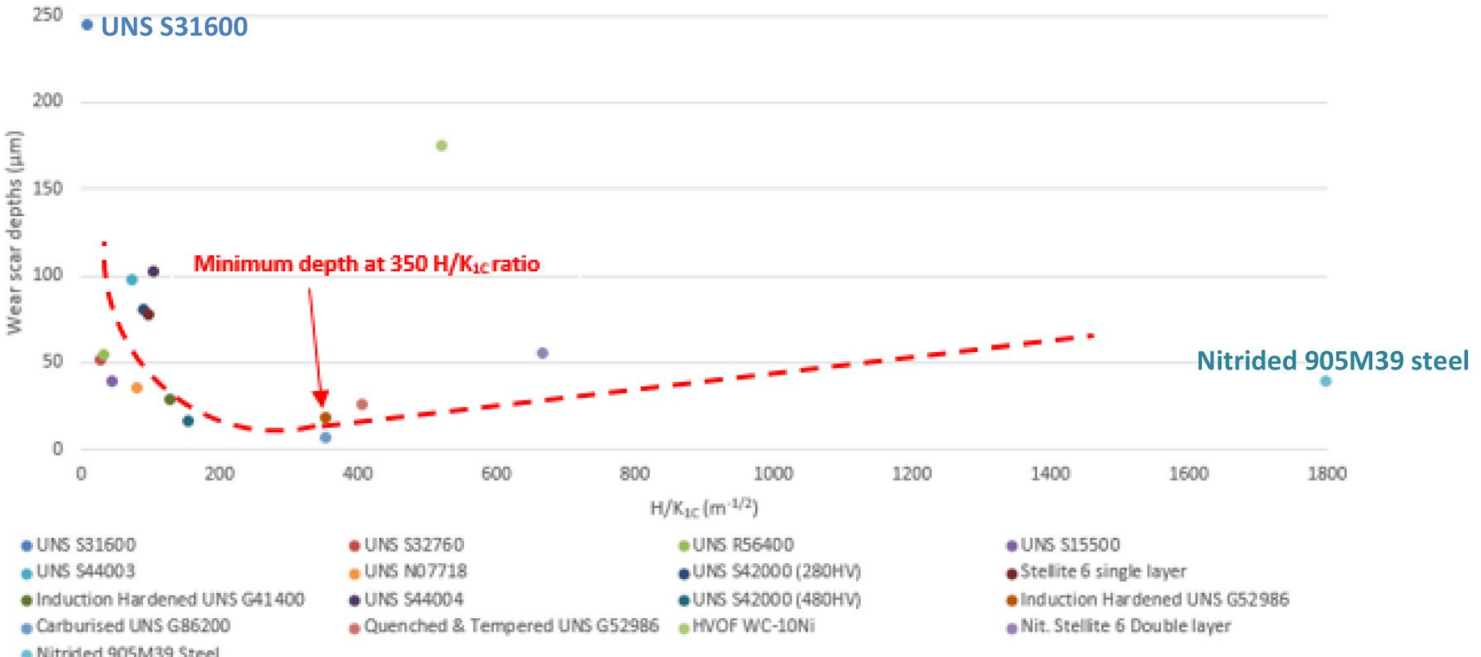

Fig. 26 Relationship between $\mathrm{H} / \mathrm{K}_{1 \mathrm{C}}$ ratio and repetitive impact wear scar depths (materials increasing with $\mathrm{H} / \mathrm{K}_{1 \mathrm{C}}$ from top left to right, row by row)

provide persuasive evidence that desired material properties for resistance to repetitive impact wear involve a delicate trade-off between hardness and fracture toughness which will clearly be dependent upon the microstructural characteristics of different materials.

\section{Conclusions}

- Novel test technique, which includes the influences of slurry, has demonstrated high degree of sensitivity between different material grades under repetitive impact wear.

- Developed test technique and assessed in non-corrosive slurry, clearly adaptable to extend the ability to assess materials under repetitive impact conditions in saline/ acidic slurries.
- Confirmed that there is no simple correlation between repetitive impact wear performance and conventional material properties such as hardness or H/E. Some evidence has been obtained of potential relationships between repetitive impact wear and $\mathrm{H} / \mathrm{K}_{1 \mathrm{C}}$.

- Demonstrated that single phase, low hardness metallic material e.g. UNS S31600 has poor performance due to inherent tendency to plastically deform.

- Good correlation between repetitive impact performance and martensitic materials (martensitic stainless steel, heat treated low alloy steel and white chromium cast iron) with reasonably high hardness.

- Coarse carbides have been shown to be vulnerable to cracking.

- Provided demonstrations of the differences in wear behaviour associated with various wear mechanisms, i.e. plastic deformation and micro-cracking, in line with 
findings of previous studies that have been in employed in different repetitive impact experimental set-ups.

Acknowledgements The authors would like to acknowledge the support for this study, which was provided by the Weir Group PLC (WARC2011-SAA1, 2011) via its establishment of the Weir Advanced Research Centre (WARC) at the University of Strathclyde.

Funding This work was funded by the Weir Group PLC (WARC2011SAA1, 2011) via its establishment of Weir Advanced Research Centre at the University of Strathclyde.

Data Availability Data not available.

\section{Compliance with Ethical Standards}

Conflict of interest No conflict of interests for authors.

Open Access This article is licensed under a Creative Commons Attribution 4.0 International License, which permits use, sharing, adaptation, distribution and reproduction in any medium or format, as long as you give appropriate credit to the original author(s) and the source, provide a link to the Creative Commons licence, and indicate if changes were made. The images or other third party material in this article are included in the article's Creative Commons licence, unless indicated otherwise in a credit line to the material. If material is not included in the article's Creative Commons licence and your intended use is not permitted by statutory regulation or exceeds the permitted use, you will need to obtain permission directly from the copyright holder. To view a copy of this licence, visit http://creativecommons.org/licenses/by/4.0/.

\section{References}

1. Engel, P.A.: Percussive impact wear. Tribol. Int. 11(3), 169-176 (1978)

2. Fisher, G., Wolfe, T., Yarmuch, M., Gerlich, A., Mendez, P.: The use of protective weld overlays in oil sands mining. Can. Weld. Assoc. J. 57(2), 28-40 (2011)

3. G. Fisher, D. Crick, J. Wolodko, D. Kichton, L. Parent 2007 "Impact testing of materials for oil sands processing applications." NACE Int. Corr. 2007.

4. ASTM G99-17 2009 "Standard Test Method for Wear Testing with a Pin-on-Disk Apparatus"

5. Rice, S.L.: Reciprocating impact wear testing apparatus. Wear $\mathbf{4 5}$, 85-95 (1977)

6. Rice, S.L.: Variations in wear resistance due to microstructural condition in high strength steel under repetitive impact. Tribol. Int. 12(1), 25-29 (1979a)

7. Rice, S.L., Nowotny, H., Wayne, S.F.: Characteristics of metallic subsurface zones in sliding and impact wear. Wear 74, 131-142 (1982)

8. Rice, S.L., Nowotny, H., Wayne, S.F.: Specimen-counterface bulk hardness effects in impact wear of 17-4 ph steel pairs. Wear 103, 175-185 (1985)

9. Rice, S.L.: The role of microstructure in the impact wear of two aluminum alloys. Wear 54(2), 291-301 (1979b)

10. Menezes, P.L., Kailas, S.V.: Subsurface deformation and the role of surface texture - a study with $\mathrm{Cu}$ pins and steel plates. Sadhana 33, 191-201 (2008)
11. Nowotny, H., Rice, S., Wayne, S.: Impact wear of a tool steel. Wear 81(1), 175-181 (1982)

12. Rice, S.L., Wayne, S.F., Nowotny, H.: Material transport phenomena in the impact wear of titanium alloys. Wear 65, 215-226 (1980)

13. Rice, S.L.: The role of specimen stiffness in sliding and impact wear. Wear 77, 13-28 (1982)

14. Su, J.F., Yu, D., Nie, X., Hu, H.: Inclined impact-sliding wear tests of TiN/A12O3/TiCN coatings on cemented carbide substrates. Surf. Coatings Technol. 206(7), 1998-2004 (2011)

15. Li, X.M., Yang, Y.Y., Shao, T.M., Jin, Y.S., Barbezat, G.: Impact wear performances of $\mathrm{Cr} 3 \mathrm{C} 2-\mathrm{NiCr}$ coatings by plasma and $\mathrm{HVOF}$ spraying. Wear 202, 208-214 (1997)

16. Fricke, R.W., Allen, C.: Repetitive impact wear of steels. Wear 162-164, 837-847 (1993)

17. Engel, P.A., Millis, D.B.: Study of surface topography in impact wear. Wear 75(2), 423-442 (1982)

18. Engel, P.A., Yang, Q.: Impact wear of multiplated electrical contacts. Wear 181-183, 730-742 (1995)

19. Blau, P.J., Hanft, T.A.: Quantitative measurement of repetitive impact damage on ground silicon nitride surfaces. Tribol. Int. 27(2), 109-118 (1994)

20. Mahoney, N.J., Grieve, R.J., Ellis, T.: A simple experimental method for studying the impact wear of materials. Wear $\mathbf{9 8}$, 79-87 (1984)

21. Lindroos, M., Apostol, M., Kuokkala, V.-T., Laukkanen, A., Valtonen, K., Holmberg, K., Oja, O.: Experimental study on the behavior of wear resistant steels under high velocity single particle impacts. Int. J. Impact Eng. 78, 114-127 (2015)

22. Naim, M., Bahadur, S.: The significance of the erosion parameter and the mechanisms of erosion in single-particle impacts. Wear 94(2), 219-232 (1984)

23. Cenna, A.A., Williams, K.C., Jones, M.G.: Analysis of impact energy factors in ductile materials using single particle impact tests on gas gun. Tribol. Int. 44(12), 1920-1925 (2011)

24. Murr, L.E., Ramirez, A.C., Gaytan, S.M., Lopez, M.I., Martinez, E.Y., Hernandez, D.H., Martinez, E.: Microstructure evolution associated with adiabatic shear bands and shear band failure in ballistic plug formation in Ti-6Al-4V targets. Mater. Sci. Eng. A 516(1-2), 205-216 (2009)

25. Duan, Z.Q., Li, S.X., Huang, D.W.: Microstructures and adiabatic shear bands formed by ballistic impact in steels and tungsten alloy. Fatigue Fract. Eng. Mater. Struct. 26(12), 1119-1126 (2003)

26. Bouzakis, K.D., Asimakopoulos, A., Batsiolas, M.: Characterization of fatigue and adhesion properties of a-C:H/CrN coatings on bearing rings by impact tests. Surf. Coatings Technol. 202(24), 5929-5935 (2008)

27. Bouzakis, K.D., Skordaris, G., Bouzakis, E., Makrimallakis, S., Kombogiannis, S., Lemmer, O.: Fatigue strength of diamond coatings' interface assessed by inclined impact test. Surf. Coatings Technol. 237, 135-141 (2013)

28. Bantle, R., Matthews, A.: Investigation into the impact wear behaviour of ceramic coatings. Surf. Coatings Technol. 74-75(2), 857-868 (1995)

29. Bouzakis, K.D., Asimakopoulos, A., Skordaris, G., Pavlidou, E., Erkens, G.: The inclined impact test: a novel method for the quantification of the adhesion properties of PVD films. Wear 262(11-12), 1471-1478 (2007)

30. Huang, J.F., Fang, H.S., Zheng, Y.K.: Influence of Re-Ti modification on the high impact wear resistance of high Si bainitic cast steel. Int. J. Miner. Metall. Mater. 17(6), 756-762 (2010)

31. Rastegar, V., Karimi, A.: Surface and subsurface deformation of wear-resistant steels exposed to impact wear. J. Mater. Eng. Perform. 23(3), 927-936 (2013) 
32. Yang, Y.-Y., Fang, H.-S., Zheng, Y.-K., Yang, Z.-G., Jiang, Z.-L.: The failure models induced by white layers during impact wear. Wear 185(1-2), 17-22 (1995)

33. Iturbe, E.B., Greenfield, I.G., Chou, T.W.: The wear mechanism obtained in copper by repetitive impacts. Wear 74(1), 123-129 (1981)

34. Kuptsov, K.A., Kiryukhantsev-Korneev, P.V., Sheveyko, A.N., Shtansky, D.V.: Comparative study of electrochemical and impact wear behavior of $\mathrm{TiCN}$, TiSiCN, TiCrSiCN, and TiAlSiCN coatings. Surf. Coatings Technol. 216, 273-281 (2013)

35. Yoon, S.Y., Yoon, S.Y., Chung, W.S., Kim, K.H.: Impact-wear behaviors of TiN and Ti-Al-N coatings on AISI D2 steel and WC-Co substrates. Surf. Coatings Technol. 177-178, 645-650 (2004)

36. Cassar, G., Banfield, S., Avelar-Batista Wilson, J.C., Housden, J., Matthews, A., Leyland, A.: Impact wear resistance of plasma diffusion treated and duplex treated/PVD-coated Ti-6Al-4V alloy. Surf. Coatings Technol. 206(10), 2645-2654 (2012)

37. Ratia, V., Valtonen, K., Kemppainen, A., Kuokkala, V.-T.: Highstress abrasion and impact-abrasion testing of wear resistant steels. Tribol. Online 8(2), 152-161 (2013)

38. Heino, V., Kaipiainen, M., Siitonen, P., Ratia, V., Rissa, K., Lepisto, T., Kuokkala, V.T.: Compressive crushing of granite with wear- resistant materials. Finnish J. Tribol. 30(1-2), 21-28 (2011)

39. Osara, K., Tiainen, T.: Three-body impact wear study on conventional and new $\mathrm{PM} /+$ HIPed wear resistant materials. Wear 250-251(1), 785-794 (2001)

40. Ratia, V., Valtonen, K., Kuokkala, V.T.: Impact-abrasion wear of wear-resistant steels at perpendicular and tilted angles. Proc. Inst. Mech. Eng., Part J: J. Eng. Tribol. 227(8), 868-877 (2013)

41. Ratia, V., Miettunen, I., Kuokkala, V.T.: Surface deformation of steels in impact-abrasion: the effect of sample angle and test duration. Wear 301(1-2), 94-101 (2013)

42. Ratia, V., Rojacz, H., Terva, J., Valtonen, K., Badisch, E., Kuokkala, V.T.: "Effect of multiple impacts on the deformation of wearresistant steels." Lett. Tribol. (2015). https://doi.org/10.1007/ s11249-014-0460-7

43. Page, N.W., Yao, M., Keys, S., Mcmillan, W., Cenna, A.: A highpressure shear cell for friction and abrasion measurements. Wear 241, 186-192 (2000)
44. Lindroos, M., Apostol, M., Heino, V., Valtonen, K., Laukkanen, A., Holmberg, K., Kuokkala, V.-T.: The deformation, strain hardening, and wear behavior of chromium-alloyed hadfield steel in abrasive and impact conditions. Tribol. Lett. 57(3), 1-11 (2015)

45. Kennedy, D.M., Hashmi, M.S.J.: Test rig design and experimental results of coated systems under impact abrasion conditions. Surf. Coatings Technol. 86-87(2), 493-497 (1996)

46. Qian, M., Chaochang, W.: Impact-abrasion behavior of low alloy white cast irons. Wear 209, 308-315 (1997)

47. Hutchings, I.M.: Mechanisms of the erosion of metals by solid particles. Eros. Prev. Useful Appl. ASTM STP 664, 59-76 (1979)

48. Wood, R.J.K., Walker, J.C., Harvey, T.J., Wang, S., Rajahram, S.S.: Influence of microstructure on the erosion and erosioncorrosion characteristics of 316 stainless steel. Wear 306(1-2), 254-262 (2013)

49. Singh, T., Tiwari, S.N., Sundararajan, G.: Room temperature erosion behaviour of 304, 316 and 410 stainless steels. Wear 145(1), $77-100(1991)$

50. L. Giourntas 2016 "Investigation of erosion-corrosion behaviour of pump materials," Ph.D. Thesis, University of Strathclyde, Glasgow.

51. Heathcock, C.J., Protheroe, B.E., Ball, A.: Cavitation erosion of stainless steels. Wear 81(2), 311-327 (1982)

52. Chintha, A.R., Valtonen, K., Kuokkala, V.T., Kundu, S., Peet, M.J., Bhadeshia, H.K.D.H.: Role of fracture toughness in impactabrasion wear. Wear 428-429, 430-437 (2019)

53. Liu, B., Li, W., Lu, X., Jia, X., Jin, X.: An integrated model of impact-abrasive wear in bainitic steels containing retained austenite. Wear 440-441, 203088 (2019)

54. Leyland, A., Matthews, A.: On the significance of the H/E ratio in wear control: a nanocomposite coating approach to optimised tribological behaviour. Wear 246(1-2), 1-11 (2000)

Publisher's Note Springer Nature remains neutral with regard to jurisdictional claims in published maps and institutional affiliations. 